\title{
Small Business in Digital Economy
}

\author{
N.V. Molotkova ${ }^{1}$, D.L. Khazanova ${ }^{1,{ }^{*}}$ and E.V. Ivanova ${ }^{2}$ \\ *Corresponding author: khazanova@ya.ru \\ ${ }^{1}$ Tambov State Technical University, Tambov, Russia \\ ${ }^{3}$ Michurinsky State Agrarian University, Michurinsk, Russia
}

\begin{abstract}
Business plays a special role in the mechanism of sustainable economic development, since it provides not only the realization of innovative potential, but also the creation of decentralized jobs, as well as additional revenues to budgets of different levels.

Periods of economic instability for small business at the local level are a big challenge, because unlike large network structures, small business does not have the ability to diversify risks due to economies of scale. Changing the vector of the national economy development has a special impact on small business, which in developed countries is a driver of economic development. Thus, the digitalization of the economic system entails fundamental changes in the processes of value-added formation: industries are being modernized, trade and procurement procedures, related financial and logistics operations are changing, and consumption patterns are changing against the background of penetration of information technologies.

The article considers two key aspects: "small business", "digitalization of the economic system". The concept of "digital economy" is considered, its key elements, distinctive features, level of development in various countries are defined. The authors also clarify the distinctive features and structure of small business in the Russian Federation. A comparative analysis of the share of small business in some countries is given, and a model for the functioning of small business at the regional level is described.

The authors identify the problems and prospects for the development of small business in a digital economy. The article tackles the issues of the impact of the digital economy on the development of small business and the role of education in this process.

The article formulates the main trends of digital transformation that have a significant role for small business at the regional level; the essence of this influence is detailed, possible barriers, new challenges and prospects for the development of small business are indicated.
\end{abstract}

Keywords: Small business, regional business, digital economy.

\section{Introduction}

Business plays a special role in the mechanism of sustainable economic development, since it provides not only the realization of innovative potential, but also the creation of decentralized jobs, as well as additional revenues to budgets of different levels. Periods of economic instability for small business at the local level are a big challenge, because unlike large network structures, small business does not have the ability to diversify risks due to economies of scale. Small enterprises today are the most vulnerable participants in the economic system. Small businesses close significantly more than new ones, as evidenced by the low share of small and medium businesses in the volume of Russia's GDP - less than $20 \%$.

Among the difficult barriers that small business face, we note:

- $\quad$ strict limitation of financial resources, including high interest rates on bank loans

- regional features of demand, namely the situation when entrepreneurs do not take into account the unique properties of the local market

- $\quad$ high transaction costs, which is typical for small manufacturing companies

- lack of strategic planning and consideration of the impact of market changes.

Despite the aggressive external environment, small business has a number of qualities that guarantee it advantages over major players in the market:

- prompt decision making

- organizational flexibility

- minimum initial investment.

Numerous studies confirm that the development of small business is correlated with the peculiarities of the socioeconomic local economic region. Thus, demographic, social, government regulation and support, as well as the availability of resources in the region, have a significant impact on the definition of regional specifics of business. However, macroeconomic changes make more serious adjustments to the activities of small business.

In December 2016, in the message of the President of Russia to the Federal Assembly of the Russian Federation (hereinafter referred to as the Russian Federation), the predominant vector of development of the economic system of the Russian Federation - the transition to the digital economy was designated "[8]. In addition, in the Decree of the President of the Russian Federation, signed on December 1, 2016 "On the strategy of scientific and technological development of the Russian Federation", digital technologies play a key role in the innovation and technological development of the state [10]. 
The program of transition to a digital economy is long-term and involves a phased implementation. In particular, until 2019, the task is to create organizational, legislative, and financial mechanisms to prepare the country to a fully digital, innovative economy [13]. The following stages imply the widespread, full-scale introduction of the digital economy, which consists in using, including in the field of small and medium-sized innovative entrepreneurship of the Russian Federation, digital, intelligent production technologies, robotic systems, as well as commercialization and export of new scientific developments [15].

\section{Problem Statement}

In the economies of developed countries, as a rule, small and medium-sized businesses occupy a significant share. Small and medium-sized enterprises (SMEs) create jobs that provide the population with income, and also determine the socio-economic situation of the country as a whole. Research results prove a high degree of relationship between the size of the SME sector and the well-being of the population and economic growth. In this regard, of particular interest is the possible impact of the transition to a digital economy on the data subject of the economic system.

\section{Research Questions}

The digital economy is a dynamically developing form of business activities of the information society. It penetrates everywhere and takes a strong position in the real sector of the economy. The emergence of new digital infrastructures, the development of computer technology and digital communications are generating new opportunities in the field of information technologies, their introduction into the socio-political and economic life of society, form a new system of the international economy - the digital one. Obviously, these conjunctive changes in the economic system actualize the task of assessing the impact of the digital economy on the main driver of the economic system - small business.

\section{Purpose of the Study}

The purpose of the study is to study the influence of the processes of digitalization of the economy on the activities of small enterprises. The authors' research is based on the works of Borodkina et al. [5], Kravchenko and Myalkina [6], Levchayev [7], Malikov and Kharisov [8], Maslennikov [9], Mukhin [10], Plaksin et al. [11], Romanova [12] and Strebkov [13].

\section{Research Methods}

The study is based on a general scientific methodology. The authors used the systems approach methods and structural-functional analysis, expert assessments and forecasting, content analysis of scientific literature, as well as monographic, abstract, logical and other methods of economic research.

The basis of this work is the fundamental works of domestic and foreign scientists devoted to the study of the digital economy, its development in the Russian Federation, as well as its influence on the development of small and mediumsized innovative entrepreneurship in Russia.

\section{Findings}

The program for the development of the digital economy in the Russian Federation until 2035 defines the term "digital economy" as follows:

Digital (electronic) economy is a combination of public relations that emerge through the use of electronic technologies, electronic infrastructure and services, technologies for analyzing large amounts of data and forecasting in order to optimize production, distribution, exchange, consumption and increase the level of social and economic development of states.

The goal of the national program for the development of the digital economy is to create favorable organizational and regulatory conditions in Russia for the effective development of the institutions of the digital economy with the participation of the state, the national business community and civil society and to ensure the rapid growth of the national economy through a qualitative change in the structure and management system of national economic assets, achieving the effect of the "Russian economic miracle" under the conditions of the global digital ecosystem [14].

The key objectives of the program are to ensure the technological leadership of the country in the context of the formation of a global digital space; the formation of a qualitatively new structure of economic assets that meet the economic priorities of the digital economy; the formation of approaches to the organization of manufacturing industries, trade, services, taking into account the achievements of the digital economy and effective in the conditions of the formation and development of the global digital space; the formation of the principles of effective management of the formed and the improvement of the management of existing economic assets (resources) and some others.

Of particular interest in the program is the task of creating conditions for the active participation of the national 
business community, including in the sector of micro, small and medium-sized businesses, operating, as a rule, at the level of one region.

Opinions in the expert community about the stage of development of the digital economy diverged. Thus, a number of specialists in the digital economy understand the result of the transformational effects of general-purpose technologies in the field of information and communication, which affect all sectors of the economy and social activity, including the sector of small and medium-sized innovative entrepreneurship that we consider.

A. Kalinin (President of the All-Russian Public Organization of Small and Medium-Sized Businesses "Support of Russia") identifies the digital economy with digitalization. Under digitalization in the study, we understand the in-depth transformation of the enterprise, implying the active use of digital technologies to optimize business processes, increase business efficiency and improve the experience of interaction with customers.

According to German Gref nowadays the society has already switched from the informational stage to the digital epoch. "We have to examine, how will business exist and how will we coexist in this new epoch: it does not matter whether you are a business owner or a usual employee, because the changes will have an impact on everyone... "Digitalization is that very new wave, which will raise the share of small business in our GDP. Serious modernisation is about to happen with all the existing enterprises, but what is the most important - digitalisation will open a great amount of new opportunities to start up own business and to succeed in it." - stated the chairman of the board of directors of JSC "Sberbank".

In the context of the investigation we approve of the position, that digital economy is a new paradigm of intercommunication of economic process participants, which bases on active usage of informational technologies, that is important to 3 stages:

- markets and economic sectors;

- platforms and technologies

- $\quad$ sphere that creates conditions for the platform and technologies development and effective interaction of market parties and economic sectors (spheres of action) and statutory regulation, informational infrastructure, manpower and informational security.

According to McKinsey \& Company estimations, up to 2025 Russian digital economy volume may rise up to 9,6 billion roubles (comparing to 3,2 billion roubles in 2015) [15]. This increase should be stimulated by digital transformation of traditional sectors and development of separate high-technological industry.

Experts in this company emphasise, that Russia is already "living in digital era". One of the most important digitalization factors is the number of internet users. According to this indicator, Russian Federation ranks the first in Europe and the $6^{\text {th }}$ in the world. It is also stimulated by increase of smartphones sales - now $60 \%$ of population have smartphones, which is higher than Brazil, India and some countries of Eastern Europe indicators. Number of state services portal users has reached the number of 40 million people. But Russia still is not one of the leaders in digital economy development because of digitalisation level, digital economy share in GDP, delays in technological inventions.

Among obvious advantages of economic system digitalisation are:

- Increase in labour productivity with the help of robotization and simultaneous decrease of production costs;

- Enterprises, that follow economic system trends, get undeniable competitive advantage comparing to other market participants, who act according to traditional format;

- New working places creation;

- Poverty and social disparity capability.

Together with that the impact may not only open new opportunities, but also create new market barriers. Among all of the market players the most sensitive to external environment changes is small business.

Today small businesses are the most vulnerable participants of economic sphere. Nowadays more small business shut down rather than open up, which is proved by the small share of middle and big enterprises in Russian GDP - less than $20 \%$. In developed countries this figure constitutes $50 \%$, also thankfully to governmental support of small enterprises. For instance, the USA indicator makes up $50 \%$, which constitutes $\$ 8$ billion.

This is nearly 22 million enterprises without the personnel and 6 million companies with employees. In Russia - 3 million sole proprietors and 2 million companies. The difference between entrepreneurial structures in Russia and in developed countries is not only quantitative, but also qualitative. It is particularly seen in fields of concern. Small businesses in the USA produce $1 / 4$ of all patents. In Russia in Research and Advanced Development sphere operate only $5 \%$ of small and middle enterprises, and their share in patent production is extremely small.

We suppose, that period of peak is the most critical for small businesses. Russian statistics states only 3,4\% of enterprises to overcome the age of 3 years. In 2017 the speed of growth of registered sole proprietors in our country remains low - the number of them increases by $7 \%$ every year, while the number of SP that stop the operations grows by $14,1 \%$. 


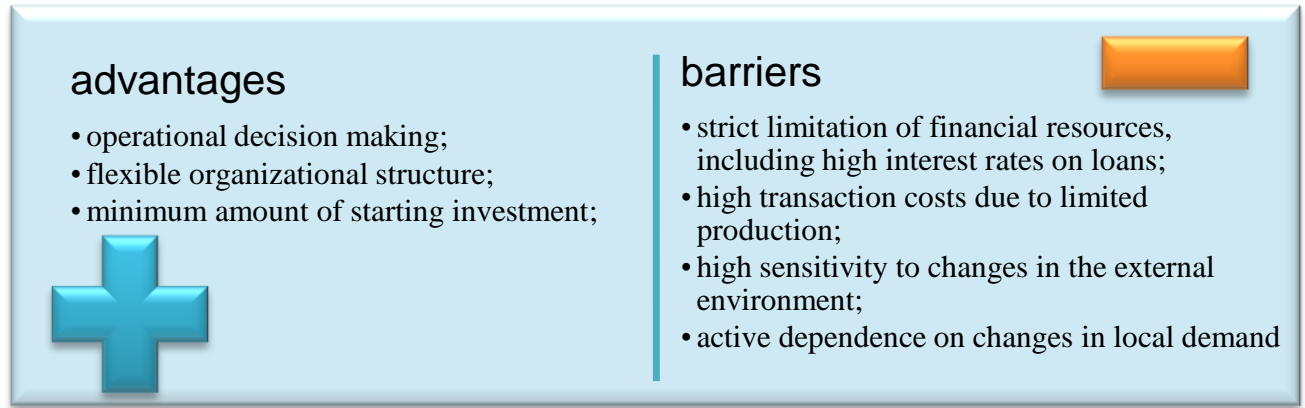

Figure 1. Strengths and weaknesses of small businesses (Source: compiled by the authors)

At the local level small business creates a specific competitive sphere which regulates the economy of the region where it operates and sets the style of its innovative development.

Describing small business, we primarily point out bilateral collaboration between the enterprise and the environmental factors. The classical approach to the investigation of the environmental factors implies their unilateral effect on an enterprise. However, in the local scale we can claim the opposite.

Practical examples can demonstrate the bilateral character of this effect. The analysis of the interconnection of the small business and the social factor has shown that the main influence of the latter on the enterprise is in the definition of the demand structure and the market volume as a whole. Thus a change in the real income of the residents of the region ensures the growth of solvency of the population and enables sales market development. At the same time an enterprise serves the labor ordering party possessing necessary knowledge and skills. Changes in demand for labor resources determine the choice of educational programs which are the residents of the region oriented at.

The effect of the investment attractiveness of the region on small business is evident, however, enterprises possessing innovation potential also increase this regional attractiveness. Investment attractiveness reflects the fact of the conformity of the region to the aims of the potential investors groups determining the investment climate of the territory and thus directly influences capital raising for the development of the business units. Investment attractiveness of the region is essential and implies active investment activity and as a result efficient social economic development of the regional economy. The estimation of the investment attractiveness of the region is a complex multifactor model which implies the estimation of the region on the whole including its normative and legislative bases, specific economic regulators as well as the activity of the specific subjects. Thus innovation potential of the specific business unit has a direct influence on the interest of the potential investors.

Considering the backward influence of small business on the peculiarity of the regional production the enterprises which might increase the scale of production have a direct effect on the regional structure of the production. Infrastructure entrepreneurship complexes which are a subsystem of the regional economy are set up during the process of scaling of the commercial activity determining fluctuations of the general structure of the regional business.

Considering the structure of small business and the basic transformational elements of the digital economy we can speak about creation of both additional and growing reserves of development. In this context the authors define the basic trends in the change of the economic system which have the largest influence on the small business:

a. Active development of the service market including outsourcing influenced by "deletion" of production boundaries.

b. Robotization

c. Change of interaction channels "business-state"

d. Rapid growth of the uber-model

Thus, to maintain the competitive advantage, small businesses should continuously monitor changes in the external environment under the influence of digitalization to assess potential opportunities and threats, as well as develop preventive protection measures and / or organic changes in the company under the conditions of the new reality.

\section{Conclusion}

Small business involves the development of a set of marketing, trading, industrial, transport and intermediary systems, which allow the local economy to change its structure, developing in various functional areas. The experience of leading European countries confirms the role of small business in the economic system as a whole. The current state of the small business does not correspond to the objectives set for the national economy, which actualizes the task of creating conditions for its hyperactive growth. At the same time, small business is the most sensitive to any changes in the external environment and falls under the significant influence of the digitalization of the economic space.

Changes in the production structure and the expansion of the boundaries of the entity's activities in the economic system have the greatest influence on small business through the universal development of the industrial Internet and cloud technologies. These are the key ones. 
- Active development of the services market, including outsourcing, under the influence of the "erasure" of production boundaries

- $\quad$ Robotization, implying the cost reduction during the entire cycle of the additional cost formation, as well as optimizing consumer product choice

- $\quad$ Rapid growth of the uber-model and development of digital platforms tightening the price resistance between market participants

- Change of interaction channels "business-state"

The research reveals new issues to be resolved.

- It is necessary to detail the problem areas of small business under the influence of digital transformation in terms of developing economic regulators and measures to support small enterprises.

- Working with foreign suppliers, who are able to drive a part of small enterprises out of the Russian market due to the low price proposal, is of great interest.

\section{References}

1. B. Panshin, Digital economy: features and development trends. Science and Innovations, 157, 17-20 (2016). [in Rus.].

2. President Decree of 01.12.2016 N 642 "On the strategy of scientific and technological development of the Russian Federation" URL: http: // www. consultant.ru/document/ cons_doc_LAW_207967. Accessed: 17/01/2019 (2016). [in Rus.].

3. N.B. Savina, Investment support for the development of economic systems. Economy: Realities of Time, 2(12): 101110-(2014). [in Rus.].

4. N.V. Studenikin, Digital technologies and new opportunities for CSR in Russia in the context of green economy, digital economy and "sharing economy". Public-private Partnership, 4, 36-40 (2017). [in Rus.].

5. V.V. Borodkina, A.V. Moskvina, O.V. Ryzhkova, Yu.V. Ulas, State support for small and medium-sized businesses in northern countries: Canada, USA, Finland, Sweden. Russian Entrepreneurship, 16(21), 3743-3764. DOI: 10.18334 / rp.16.21.2074 (2015). [in Rus.].

6. M.V. Kravchenko, A.F. Myalkina, Problems of applying special tax regimes for small businesses in the Russian Federation. Socio-economic Phenomena and Processes, 10(3), 34-40 (2015). [in Rus.].

7. P.A. Levchayev, Features of the activities of economic entities in the information economy. Bulletin of the University of Mordovia, 3, 110-115 (2009). [in Rus.].

8. R.I. Malikov, V.I. Kharisov, Development of a risk assessment tool for the implementation of infrastructure projects for the development of entrepreneurship. Economy of the Region, 4(36), 199-208 (2013). [in Rus.].

9. M.I. Maslennikov, Technological innovation and its impact on the economy. Economy of the Region, 13(4), 12211235 (2017). [in Rus.].

10. A.V. Mukhin, The value of small business in regional economic systems. Business in Law. Economic and Legal Journal, 2, 264-266 (2011). [in Rus.].

11. S. Plaksin, G. Abdrakhmanova, G. Kovaleva, Internet economy in Russia: Approaches to the definition and assessment. Forsyth, 11(1), 55-65 (2017). [in Rus.].

12. O.A. Romanova, Industrial Policy Priorities of Russia in the Context of Challenges of the Fourth Industrial Revolution. Part 2. Economy of the Region, 14(3), 806-819 (2018). [in Rus.].

13. D.O. Strebkov, The innovative potential of agents of the new economy. Forsyth, 4(2), 26-33 (2010). [in Rus.].

14. Government of the Russian Federation, Development of digital economy in Russia. Program until 2035. URL: http://static.government.ru/media/files/9gFM4FHj4PsB79I5v7yLVuPgu4bvR7M0.pdf. Accessed: 17/01/2019 (2017). [in Rus.].

15. McKinsey \& Company, Digital Russia: New reality, Report. "URL: https://www.mckinsey.com/ /media/McKinsey/Locations/Europe\%20and\%20Middle\%20East/Russia/Our\%20Insig hts/Digital\%20Russia/Digital-Russia-report.ashx. Accessed: 17/01/2019 (2017). [in Rus.]. 